\title{
Role of Low Level Laser Therapy (LLLT) in Prevention of Hypertrophic Scarring
}

\author{
Sireesha KR, Chittoria RK*, Preethitha B, Elan kumar S, Vinayak C, \\ Kumaran S, Sudhanva HK, Aggarwal A and Saurabh Gr \\ Department of Plastic Surgery, Jawaharlal Institute of Postgraduate Medical \\ Education and Research (JIPMER), India
}

*Corresponding author: Ravi Kumar Chittoria, Professor\& Registrar (Academic), Department of Plastic Surgery, Jawaharlal Institute of Postgraduate Medical Education and Research (JIPMER), Pondicherry, India, E-mail: drchittoria@yahoo.com

\section{Abstract}

Low level lasers (LLL) are lasers with a wave-length 600 and 1000 nanometers and power ranging from 5 to 500 Mw. The bio-stimulatory properties of LLL have been found to accelerate wound healing, tissue repair and regeneration. Low level Laser (LLL) has been tested to treat established hypertrophic scarring but it has not been studied in the prevention. The fact that preventing hypertrophic scarring is far easy than treating, hence keeping this fact in mind this study tested the role of Low Level Laser Therapy (LLLT) in prevention of development of hypertrophic scarring.

Keywords: Hypertrophic scarring; Low Level Laser Therapy (LLLT); Prevention

Abbreviations: LLL: Low level lasers; LLLT: Low Level Laser Therapy; VSS: Vancouver scar scale; LASER: Light Amplification by Stimulated Emission of Radiation.

\section{Introduction}

Endre Mester, a Hungarian physician initiated the use of Low level laser therapy (LLLT) in 1960 which received FDA approval in the early 1990's. Low Level Laser (LLL) do not produce any heat in contrast to cutting or ablative lasers used in medicine [1]. When given for short duration and energy $(<4 \mathrm{~J})$, they have been found to have biostimulatory effects on wound healing [2].

Low level laser therapy (LLLT) differs from traditional ablative or cutting lasers by the low energy density it delivers and its non-thermal mechanism. Posten, et al. described following properties of low level lasers:
1. Power output $-0.001-0.1$ watts

2. Wave length - 300-10,600 nm

3. Pulse rate - $0-5000$ hertz (cycles per second)

4. Dose 0.01 to $100 \mathrm{~J}$.

We found low level laser therapy as an effective adjunct in prevention of hypertrophic scars and through this article we would like to highlight the use of Low level laser therapy (LLLT) in prevention of hypertrophic scars $[1,2]$.

\section{Case Report}

A 35 yrs male came with history of accidental electrical flash burns on his face and bilateral upper limbs. Total body surface areas of burns were calculated and fluid resuscitation was started. Patient was admitted and evaluated further. 


\section{Medical Journal of Clinical Trials \& Case Studies}

Patient was started on high protein diet with supplemental nutrition. Patient was treated with Hydro jet debridement, collagen dressing, low level laser therapy (LLLT) using gallium arsenite laser for 10 minutes along the healed areas of burns and splinting of both hands in functional position. Laser safety and precautions were maintained as per international standards. LLLT was repeated twice every week even after the complete healing of raw areas. Low level laser therapy (LLLT) was continued for 3 months. Patient is followed up for 6 months. Healed areas assessed using Vancouver scar scale (VSS). No hypertrophic scar was noticed.

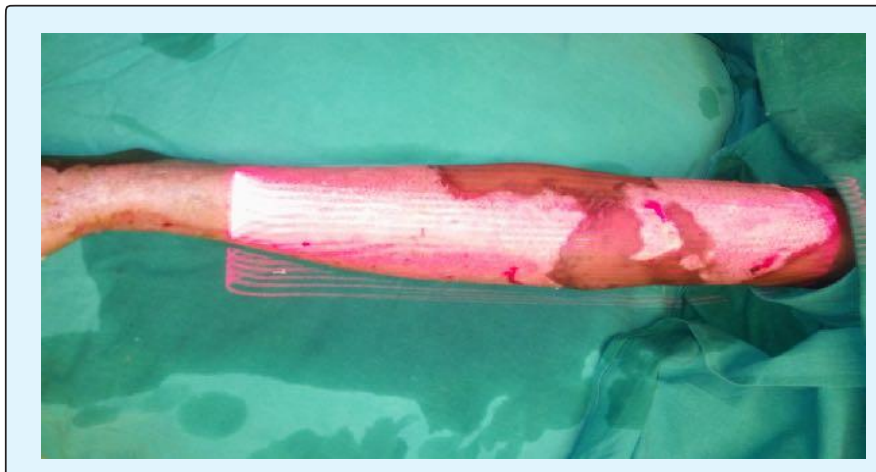

Figure 1: LLLT being given.
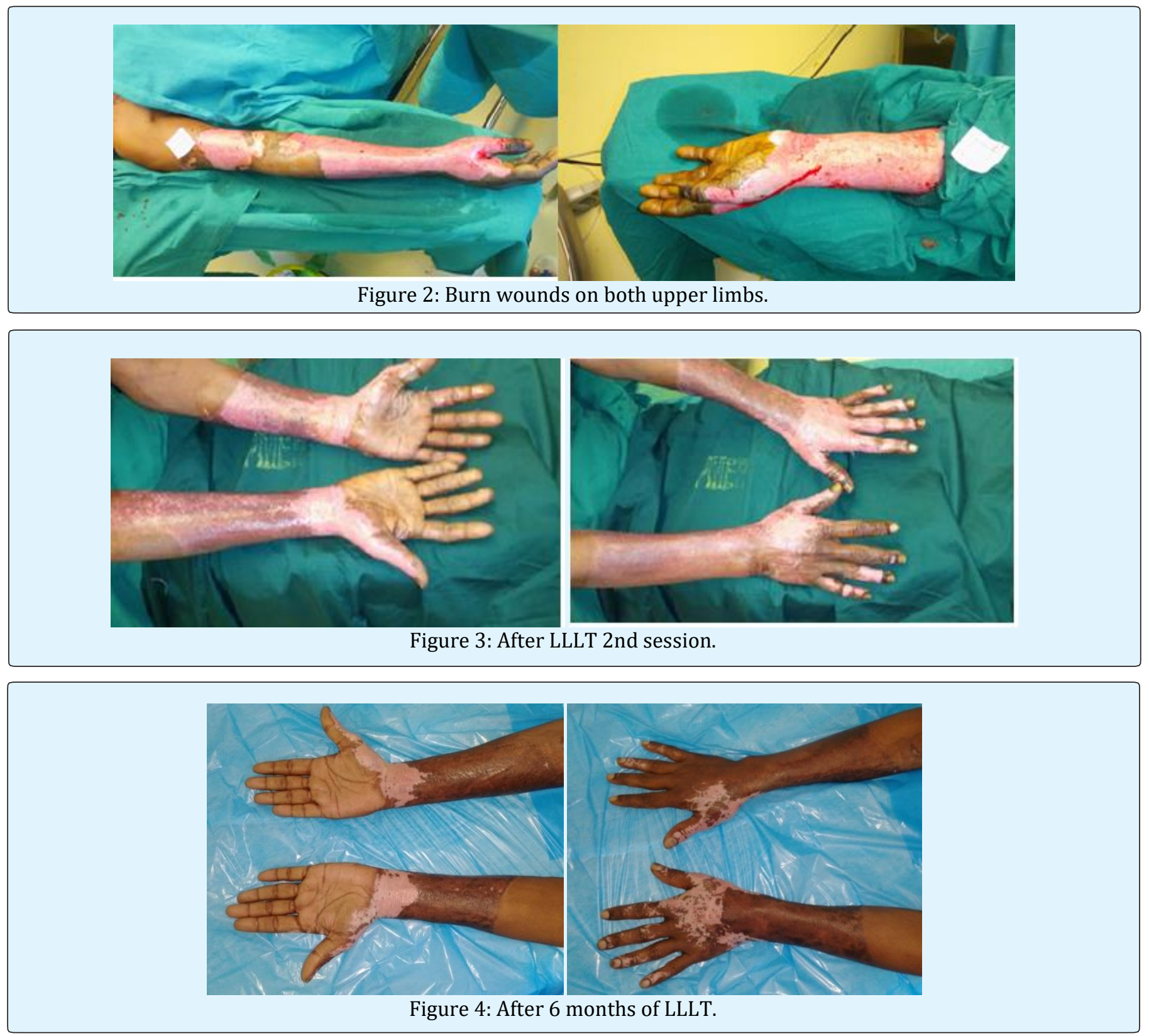


\section{Medical Journal of Clinical Trials \& Case Studies}

\section{Discussion}

LASER (Light Amplification by Stimulated Emission of Radiation) since its invention in 1960 and its first utility in the biomedical field in 1983 continues to evolve and improve technologically with the spectrum of its utility in the medical field expanding exponentially [3].

Commonly used LASERS for LLLT include gallium aluminum arsenide Ga-Al-As (805 or $650 \mathrm{~nm}$ ), gallium arsenide Ga- As (904 nm), Krypton (521, 530, 568, and $647 \mathrm{~nm}$ ), argon $\mathrm{Ar}$ (488 and $514 \mathrm{~nm}$ ), helium neon He-Ne $(632.8 \mathrm{~nm})$ and ruby $(694 \mathrm{~nm})$. LLLT has known to have bio-stimulatory effects on wound healing to augment tissue repair and regeneration along with its antiinflammatory and analgesic effects [2]. It has also been used for photo rejuvenation of photo damaged skin, wrinkles and scars [4].

The following biological effects of low level laser therapy include decrease in inflammatory cells, decreased synthesis of inflammatory mediators, increased secretion of growth factors, increase in proliferation of fibroblasts, increase in collagen synthesis, simulation of angiogenesis $\&$ stimulation for formation of granulation tissue [5]. The photo biological effects of low level laser therapy depends on the wavelength, dose, power and duration of application [6].

\section{Conclusion}

We have observed that the chances of healed areas to become into hypertrophic scars are very much less after giving LLLT.
The limitation of this observation is that it is done in single case. Study with large sample size and control group included has to be done.

\section{References}

1. Barrett S (2009) A Skeptical Look at Low Level Laser Therapy. Quack watch.

2. Lin F, Josephs SF, Alexandrescu DT, Ramos F, Bogin V, et al. (2010) Lasers, stem cells, and COPD. J Trans Med 8: 16.

3. Posten W, Wrone DA, Dover JS, Arndt KA, Silapunt S, et al. (2005) Low-level laser therapy for wound healing: mechanism and efficacy. Dermatol Surg 31(3): 334-340.

4. Kneebone WJ (2006) Practical applications of low level laser therapy. Practical Pain Management 6(8): 34-40.

5. Chaves M, Angélica Rodrigues de Araújo, André Costa Cruz Piancastelli, Marcos Pinotti (2014) Effects of low-power light therapy on wound healing: LASER $\mathrm{x}$ LED. An Bras Dermatol 89(4): 616-623.

6. Andrade F, Rosana C, Manoel F (2014) Effects of lowlevel laser therapy on wound healing. Rev Col Bras Cir 41(2): 129-133. 